\title{
Major Ion Chemistry and Groundwater Quality Evaluation for Irrigation
}

\author{
${ }^{*}$ SHYAMALA, G; ${ }^{2}$ RAMESH, S; ${ }^{3}$ SARAVANAKUMAR, N \\ *1Department of Civil Engineering, $S R$ Engineering College, Warangal, India \\ ${ }^{2}$ Department of Civil Engineering, K.S.Rangasamy College of Technology, Tamilnadu, India \\ ${ }^{3}$ Department of Civil Engineering, Arba minch university, Sawla Campus, Ethiopia \\ *Corresponding Author Email: shyamala@srecwarangal.ac.in
}

\begin{abstract}
Hydrogeochemical characteristics of Groundwater analyzed in the study area of Coimbatore district by collecting 60 samples from agricultural belt. Groundwater quality for irrigation is determined by several key factors like $\mathrm{pH}$, Electrical conductivity (EC), Total suspended solids (TDS). The cations such as Sodium $\left(\mathrm{Na}^{+}\right)$, Potassium $\left(\mathrm{K}^{+}\right)$, Calcium $\left(\mathrm{Ca}^{2+}\right)$, Magnesium $\left(\mathrm{Mg}^{2+}\right)$ and anions are Hydrocarbon $\left(\mathrm{HCO}_{3}\right)$, Carbonate $\left(\mathrm{CO}_{3}^{-}\right)$, Chlorides $\left(\mathrm{Cl}^{-}\right)$and Sulphates $\left(\mathrm{SO}_{4}{ }^{2-}\right)$ are tested. The irrigation water quality parameters such as Residual Sodium Carbonate (RSC), Sodium Absorption Ratio (SAR), Chloro Alkali Indices (CA I \& CAII), Kelley's Ratio (KR), Magnesium Hazard (MH), Percent sodium (\%Na) and Permeability Index (PI), Soluble sodium Percent (SSP) are computed from the key factors, anions and cations. From the USSL Diagram the samples fall in C2S1, C3S1, C4S1 range. Salinity hazard is too elevated in the study area, all the samples are categorized under high to very high with the values greater than $750 \mu \mathrm{S} / \mathrm{cm}$. Total dissolved solid in the study area indicated that only 2 locations are unfit for irrigation. SAR and \% Na shows that there is no hazard related to irrigation watering. Magnesium hazard in the groundwater is high and indicates 51 sample out of 60 is unsuitable for irrigation. From the study it indicates the groundwater is contaminated with salt content and in most of the area it can be used for irrigation.
\end{abstract}

DOI: $\underline{\text { https://dx.doi.org/10.4314/jasem.v24i4.23 }}$

Copyright: Copyright (C) 2020 Shyamala et al. This is an open access article distributed under the Creative Commons Attribution License (CCL), which permits unrestricted use, distribution, and reproduction in any medium, provided the original work is properly cited.

Dates: Received: 07 February 2020; Revised: 19 March 2020; Accepted: 27 March 2020

Keywords: Groundwater, Irrigation water quality, Salinity hazard, Kelley’s ratio, Magnesium hazard

Management of groundwater is vital for the sustainable growth of nation. From the past decade groundwater is becoming an important source of water supply worldwide(Yousif et al., 2013). It is known for its natural protection from contaminants. Gradually the groundwater quality has worsened in some provinces, leading to bitter consequences. Removing pollutants from the groundwater is a challenging task, sometime impossible due to its long residence time (Ahamed and Jayakumar 2015). Quality of groundwater is likewise significant to its quantity owing to the suitability of groundwater for numerous functions(Shyamala et al.,. 2017). Groundwater is an essential component of our life support system. Groundwater is less contaminated contrasted with surface water, anyway because of fast development of population, urbanization, industrialization and rural growth, groundwater assets are under danger(Srinivas et al., 2015). Soil layers and rock contains minerals which get disintegrated in groundwater as it goes through it. Hurtful contaminants get related with the groundwater through the procedure of leakage from the surface water and natural factors(Selvakumar et al., 2014)(Krishna et al., 2016). The chemical composition of groundwater is constrained by numerous elements, including the precipitation, topographical structure, mineralogy of springs, land forms inside the spring, alongside effect of outside contamination like releases from agricultural activity, industrial activity and urbanization(Aghazadeh and Mogaddam 2010)(Ahamed and Jayakumar 2015). Ramkumar conducted studies to estimate the water quality of Kottur block, Thiruvarur district, Tamil Nadu. Control of cations in the order of $\mathrm{Na}^{+}>\mathrm{Ca}^{2+}>\mathrm{K}^{+}$ $>\mathrm{Mg}^{2+}$ and anions $\mathrm{Cl}^{-}>\mathrm{So}_{4}{ }^{2-}>\mathrm{HCO}_{3}{ }^{-}>\mathrm{No}_{3}$ was observed in both seasons(Ramkumar et al., 2013). Oyem analysed the concentration of selected heavy metals in the groundwater. The result of this analysis did not reveal any strong or significant inter-metal relationship in the groundwater. (Oyem and Usese, 2015). Srinivas collected and examined the groundwater samples according to published guide lines. Sodium is the most dominant cation when compared with chlorides and hydrocarbonate. Total dissolved solid ranges between 67 and $2086 \mathrm{mg} / \mathrm{l}$ with a mean of $523 \mathrm{mg} / 1$ (Srinivas et al., 2015). (Shyamala et al. 2020).

Nishanthiny conducted groundwater quality analysis based on irrigation water quality. Residual sodium carbonate was used to find suitability of groundwater for irrigation use. Overall assessment of the tested well 
indicated very well that $20.6 \%$ wells have a good quality of water and $44.1 \%$ of the well have permissible to desirable irrigation water quality and $35.3 \%$ of the well have a unsuitable irrigation water quality(Ramesh et al., 2020). High SAR in irrigation water transforms the physical construction of the soil particles. Soil particles are attracted towards sodium and adsorbed on the surface, making soil impervious(Mohamed et al. 2018). Salinity condition exists as salt gets accumulated in the root zone of the plants, if the groundwater with high TDS is irrigated continuously. Shanmugasundharam used Wilcox diagram to determine the aptness of groundwater for irrigation purpose. (Shanmugasundharam et al., 2015). Venkateswaran and Vediappan (2013) investigated suitability of groundwater quality for agricultural use in lower Bhavani reservoir. $\mathrm{He}$ computed sodium kelley ratio, absorption ratio, magnesium hazard, Percentage Sodium Permeability Index and Residual Sodium Carbonate(RSC) along with wilcox diagram and USSL diagram. High salinity was observed in most of the location, hence ample drainage should be provided to improve crop yield (Shyamala et al.,. 2020)(Shyamala and Jeyanthi 2017).

\section{MATERIALS AND METHODS}

Study area: Coimbatore is agriculture based district with the area of $4723 \mathrm{sq} \mathrm{km}$. It is situated at the altitude of 411 meters above mean sea level. It is one of the largest city in Tamil Nadu state Coimbatore District is composed of rocks of Dharwar age, which is of high grade metamorphic rocks. The hydro geological framework of the district is controlled by the distribution of rainfall, geological structure and morphological configuration. The area is covered by metamorphic rock of type archean, alluvium, colluviums, laterite, charnockite, hornblende, biotite gneiss, garnet sillmanite gneiss, pegmatite and quartz veins. To initialize the task of groundwater quality assessment visit was made to the irrigation fields and residential area to identify potential of groundwater in the area. Depth of the sample extraction in the study area was in the range of $30 \mathrm{ft}$ to $250 \mathrm{ft}$. In total 60 groundwater samples have been drawn from borewells and open wells. The samples were gathered in plastic containers, sanitized with distilled before gathering groundwater.

\section{RESULTS AND DISCUSSION}

Irrigation water quality parameters: In the study area of Coimbatore district 60 samples were collected from agricultural belt. Water quality for irrigation is determined by several key factors like Salinity Hazard (SH), Sodium Absorption Ratio (SAR), Total
Suspended Solids (TDS), Percent Sodium (\%Na), Residual Sodium Carbonate (RSC), Kelley's Ratio (KR), Magnesium Hazard (MH), Chloro Alkali Indices (CAI \& CAII), Soluble sodium Percent (SSP) and Permeability Index (PI)(Prasanna et al.,. 2011), (K. Ramesh and Vennila 2012), (Magesh and Chandrasekar 2013). Quality of water for irrigation is determined by several key factors as shown in the Table 1.

Table 1 Minimum and maximum value of irrigation water quality

\begin{tabular}{lllll}
\multicolumn{5}{c}{ parameters } \\
\hline S. No. & Variable & Minimum & Maximum & Mean \\
\hline 1 & SAR (mg/l) & 1.81 & 9.30 & 5.24 \\
2 & \% Na & 17.088 & 52.52 & 38.76 \\
3 & RCS (mg/l) & 0.134 & 1.32 & 0.425 \\
4 & KR (mg/l) & 0.123 & 0.706 & 0.375 \\
5 & MH (mg/l) & 36.56 & 77.44 & 57.31 \\
6 & CA I(mg/l) & -17.64 & 0.47 & -1.054 \\
7 & CA II(mg/l) & -0.964 & 3.643 & 0.542 \\
8 & SSP & 10.8564 & 41.369 & 25.62 \\
9 & PI & 21.076 & 77.939 & 41.889 \\
\hline
\end{tabular}

Salinity Hazard: Electrical conductivity is excellent measure to determine salinity hazard to crops as it reveal TDS in groundwater(B Arun Kumar et al. 2018). High EC indicates elevated salt content water. Excess salinity will reduce the osmotic activity of plants and thus hinder with the assimilation of water and nutrients from the soil. EC indicates the presence of sodium \& chloride ions, which may be due to the use of fertilizer in turn due to fertilizers. Ions may be positively or negatively charged, which are produced by breaking of compounds that conduct electricity. Mobility of ions dissolved in water increases conductivity. Total dissolved solids can be indirectly measured from electric conductivity. Limiting value for electrical conductivity is provided in the Table 4.4, out of 60 samples tested none of the samples are in the category of low or medium. High electrical conductivity is observed in 54 samples and 6 samples are of very high electrical conductivity i.e. in the range greater than $2250 \mu \mathrm{S} / \mathrm{cm}$. USSL diagram is plotted for electrical conductivity and sodium absorption ratio. Most of the samples fall in low SAR and high to very high EC range as shown in Figure 1.

Table 2 Categorization of irrigation water quality based on EC

\begin{tabular}{llll}
\hline S. No & Limiting value & category & No. of samples \\
\hline 1 & $<250(\mu \mathrm{S} / \mathrm{cm})$ & Low & - \\
2 & )$-750 \mu \mathrm{S} / \mathrm{cm})$ & Medium & - \\
3 & $750-2250(\mu \mathrm{S} / \mathrm{cm})$ & High & 54 \\
4 & $>2250(\mu \mathrm{S} / \mathrm{cm})$ & Very high & 6 \\
\hline
\end{tabular}

Total dissolved solids can be indirectly measured from electric conductivity. Limiting value for electrical conductivity is provided in the Table 2 , out of 60 samples tested none of the samples are in the category of low or medium. High electrical conductivity is 
observed in 54 samples and 6 samples are of very high electrical conductivity i.e. in the range greater than $2250 \mu \mathrm{S} / \mathrm{cm}$.

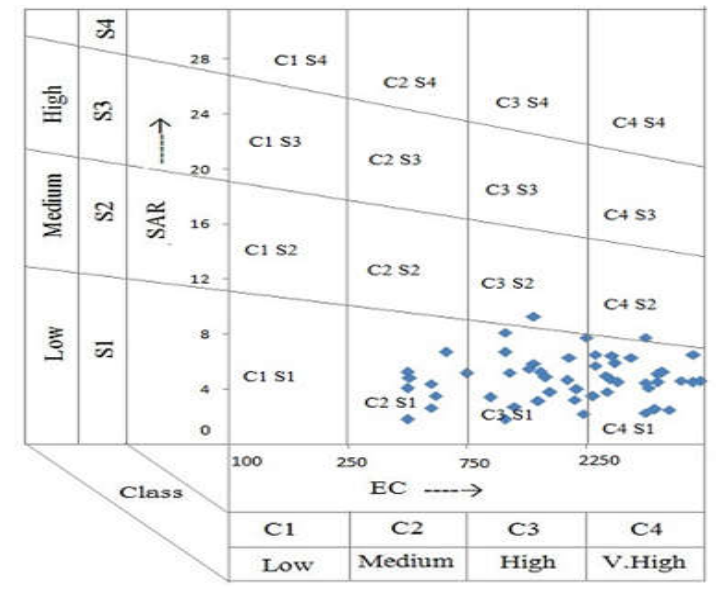

Fig. 1 USSL diagram for Salinity Hazard

Total Dissolved Solids: Groundwater contains negligible quantity of suspended solid as these are filtered out by soil strata through mechanical straining action (Omonona et al., 2014). The amount of suspended solids in groundwater increases with input of manmade contamination. Total Suspended Solids in the study location is shown in the Table 4.5. In 60 Samples considered for analysis 58 samples are fit for agricultural usage and 2 samples are unfit for both potable drinking and agricultural usage. Presence of Total Dissolved Solids is owing to sediments or the contact of water with atmosphere or soil.

Table 3. Categorization of irrigation water quality based on TDS

\begin{tabular}{llll}
\hline S. No & $\begin{array}{l}\text { Limiting } \\
\text { value }\end{array}$ & Category & $\begin{array}{l}\text { No. } \\
\text { samples }\end{array}$ \\
\hline 1 & $<500$ & Fit for drinking & - \\
2 & $500-$ & Unfit for drinking & 14 \\
3 & 1000 & Useful for irrigation & 44 \\
4 & $<3000$ & $\begin{array}{l}\text { Unfit for drinking and } \\
\text { irrigation }\end{array}$ & 2 \\
\hline
\end{tabular}

Sodium Absorption Ratio: Suitability of groundwater for agricultural use is found by Sodium Adsorption Ratio. Continuous usage of water with high SAR may cause prolonged dent to soil. Due to formation of stable aggregates and soil structures is affected. Permeability of soil is reduced and in turn crop yield is decreased. Sodium adsorption ratio (SAR) is calculated by means of the following formula 1

$$
\mathrm{SAR}=\frac{\mathrm{Na}^{+}}{\sqrt{\left(\mathrm{Ca}^{2+}+\mathrm{Mg}^{2+}\right) / 2}} \quad 1
$$

If the SAR is less than 3.0 the groundwater can be used for all varieties of crops. For sensitive crop the usage should be minimized if SAR Value is in the range of 3-6. Categorization of groundwater based on SAR is given in the Table 4.

Table 4. Categorization of irrigation water quality based on SAR

\begin{tabular}{llll}
\hline S. No & $\begin{array}{l}\text { Limiting } \\
\text { value }\end{array}$ & category & $\begin{array}{c}\text { No. of } \\
\text { samples }\end{array}$ \\
\hline 1 & $0-3$ & No problems & 45 \\
2 & $3-6$ & Moderate problems & 15 \\
3 & $>6$ & :vere problems & 0 \\
\hline
\end{tabular}

Percent sodium: Percent sodium is determined from the values of sodium, potassium, calcium and magnesium. Occurrence of sodium in groundwater is represented by soluble sodium or percent sodium. Sodium percent is classified in to five types unsuitable, doubtful, permissible, good and excellent. Percent sodium is computed using the equation 2 .

$$
\% \mathrm{Na}=\frac{\left(\mathrm{Na}^{+}+\mathrm{K}^{+}\right) \times 100}{\left(\mathrm{Ca}^{2}+\mathrm{Mg}^{2}+\mathrm{Na}^{+}+\mathrm{K}^{+}\right)} \quad 2
$$

Table 5. Categorization of irrigation water quality based on Percent Sodium

\begin{tabular}{llll}
\hline S. No & $\begin{array}{l}\text { Limiting } \\
\text { value }\end{array}$ & category & $\begin{array}{l}\text { No. of } \\
\text { samples }\end{array}$ \\
\hline 1 & $<20$ & Excellent & 1 \\
2 & $20-40$ & Good & 35 \\
3 & $40-60$ & Permissible & 24 \\
4 & $60-80$ & Doubtful & - \\
5 & $>80$ & Unsuitable & - \\
\hline
\end{tabular}

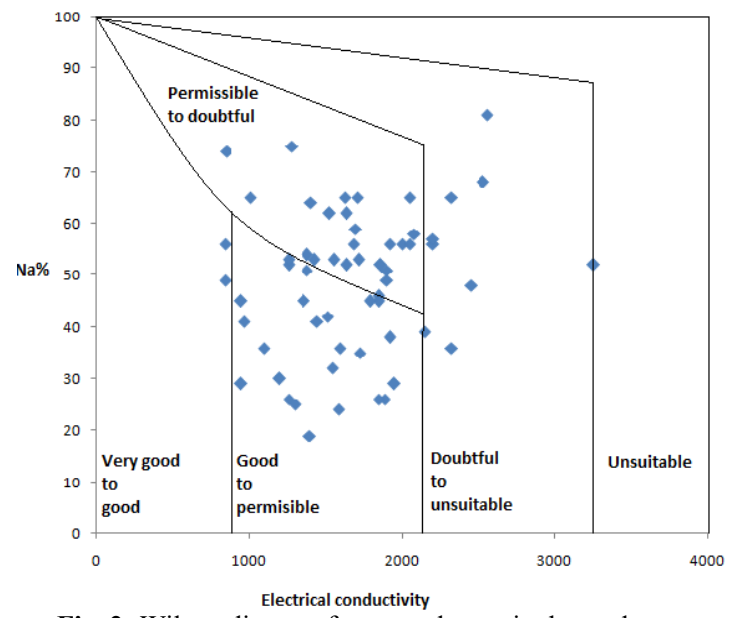

Fig. 2: Wilcox diagram for groundwater in the study area

All the samples in the study location are in $60 \%$ hence it falls in the range of excellent to permissible category (Table 5). As per sodium concentration the groundwater does not have negative impacts like growth retardation or yield reduction. Table 5 shows the categorization of agricultural water quality based on percent sodium. All the 60 samples fall in the group of excellent to permissible category. Electrical conductivity and percentage sodium is represented in 
Wilcox diagram. Wilcox diagram (Fig. 2) is used to evaluate the appropriateness of groundwater for irrigation using percent sodium and electric conductivity. It is categorized ad very good to good, Good to permissible, Doubtful to unsuitable, unsuitable and permissible to doubtful. In the study area most of the sample fall in three categories Good to permissible, Doubtful to unsuitable and permissible to doubtful.

Residual Sodium Carbonate: Water with a carbonate concentration larger than the calcium and magnesium concentration is recognized by the term "residual sodium carbonate". Residual Sodium Carbonate index (RCS) refers alkalinity hazard to soil. If the sodium in clayey soil is higher it causes swelling and reduces infiltration capacity. The potential of sodium vulnerability is increased as Residual sodium carbonate (RSC) raise. Residual Sodium Carbonate (RSC) is intended from the formula 3

$$
\mathrm{RSC}=\left(\mathrm{CO}_{3}^{2-}+\mathrm{HCO}_{3}^{-}\right)-\left(\mathrm{Ca}^{2+}+\mathrm{Mg}^{2+}\right)
$$

To identify the aptness of groundwater in clay soil RCS index is used. If the groundwater with elevated RCS is applied for irrigation it leads to alkali soil formation. As per calculated RCS index for the 60 samples collected in agricultural belt, 58 samples have low RCS value less than 1.25 and is apt for irrigation as shown in the Table 6 .

\begin{tabular}{llll}
\multicolumn{2}{c}{ Table 6. } & Classification of irrigation water quality based on RSC \\
\hline S. No & Limiting value & category & No. of samples \\
\hline 1 & $<1.25$ & Good & 58 \\
2 & $1.25-2.50$ & Doubtful & 2 \\
3 & $>2.50$ & Unsuitable & - \\
\hline
\end{tabular}

Kelly's Ratio: $m$ : Kelley Ratio indicates the highest value of sodium in the groundwater. The formula 4 is applied in the inference of Kelley's ratio and is articulated as,

$$
\mathrm{KR}=\frac{\mathrm{Na}^{+}}{\left(\mathrm{Ca}^{2+}+\mathrm{Mg}^{2+}\right)}
$$

Kelley's proportion (KR) of more than 1 reveals to an abundance level of sodium in waters. Subsequently, waters with a Kelley's Ratio are most suitable for irrigation, while those with a proportion more than one are unacceptable for irrigation. 60 samples were analysed in the agricultural area and the Kelley ratio falls less than 1 for all the samples which shows the groundwater is apt for irrigation in the study area (Table 7).

Table 7. Classification of irrigation water quality based on KR

\begin{tabular}{llll}
\hline S. No & Limiting value & Category & No. of samples \\
\hline 1 & $<1$ & Suitable & 59 \\
\hline
\end{tabular}

\begin{tabular}{llll}
\hline 2 & $>1$ & Unsuitable 1
\end{tabular}

Magnesium Hazard: Groundwater with elevated concentration of magnesium, if used for irrigation purpose damages soil structure and causes high salinity. Calcium and magnesium are present in water in an equilibrium state and they behave independently in soil system. Magnesium hazard is given by the equation 5

$$
\mathrm{MH}=\frac{\mathrm{Mg}^{+} \mathrm{X} 100}{\left(\mathrm{Ca}^{2+}+\mathrm{Mg}^{2+}\right)} \quad 5
$$

From the analysis $\mathrm{MH}$ value for the samples are in the ranges from 35.68 to 77.89 . MH value should be less than $50 \mathrm{meq} / 1$, Out of 60 samples 9 samples were apt for agriculture as per magnesium hazard revealed in the table 4.10. If the magnesium hazard value is greater than $50 \mathrm{meq} / \mathrm{l}$ it affects plant growth and becomes unsuitable for agricultural use, In the widely held number of the samples in the study area i.e in about 51samples the Magnesium Hazard value is above 50meq/1 which makes it unsuitable for agricultural use.

Table 8. Categorization of irrigation water quality based on $\mathrm{MH}$

\begin{tabular}{llll}
\hline S. No & Limiting value & Category & No. of samples \\
\hline 1 & $<50$ & Suitable & 9 \\
2 & $>50$ & Unsuitable & 51 \\
\hline
\end{tabular}

Total hardness as $\mathrm{CaCO}_{3}$ : Hardness in water is brought about by the occurrence of divalent metallic cations like calcium, magnesium, ferrous iron, strontium, manganese and so on. It is relevant to take note of that the greater part of the industrial sector in the zone pre-treat water to evacuate hardness; else it blocks the working of their boilers. In the examination zone 56 examples are in the class of hard to hard.

\begin{tabular}{llll}
\multicolumn{4}{c}{ Table 9. Categorization of irrigation water quality based on TH } \\
\hline S. No & Limiting value & category & No. of samples \\
\hline 1 & $<75$ & Soft & - \\
2 & $75-150$ & Moderately hard & 3 \\
3 & $150-300$ & Hard & 36 \\
4 & $>300$ & Very hard & 20 \\
\hline
\end{tabular}

Soluble sodium Percent (SSP): Soluble Sodium Percent (SSP) for groundwater was determined by using the formula 4.6. The groupings of $\mathrm{Ca} 2+, \mathrm{Mg} 2+$ and $\mathrm{Na}+$ are articulated in mill equivalents per liter. The solvent Sodium Percent (SSP) values under 50 or equivalent to 50 signify great quality water and in the event that it is in excess of 50 it denotes the intolerable water quality for water for irrigation(Kshetrimayum and Bajpai 2012).

$$
\mathrm{SSP}=\frac{\mathrm{NaX} 100}{\mathrm{Ca}^{2+}+\mathrm{Mg}^{2+}+\mathrm{Na}^{+}} \quad 6
$$


Permeability Index: Permeability index of the groundwater is calculated using sodium, carbonates, calcium and magnesium. Groundwater for irrigation is investigated dependent on the Permeability Index (PI). PI is computed from the equation 7.

$$
\mathrm{PI}=\frac{\left(\mathrm{Na}^{+}+\sqrt{\left.\mathrm{HCO}_{3}\right)} \times 100\right.}{\left(\mathrm{Ca}^{2+}+\mathrm{Mg}^{2+}+\mathrm{Na}^{+}\right)} \quad 7
$$

Table 10. Categorization of irrigation water quality based on PI

\begin{tabular}{llll}
\hline S. No & Limiting value & Category & No. of samples \\
\hline 1 & $<25 \%$ & Class I & 1 \\
2 & $25-75 \%$ & Class II & 58 \\
3 & $>75 \%$ & Class III & 1 \\
\hline
\end{tabular}

Accordingly, the permeability index is classified under class I, class II and class III . Based on the limiting values, less than $25 \%$ it is classified as class I, $25 \%$ to $75 \%$ it is classified as class II and greater than 75 $\%$ it is classified as Class III as shown in the table 10 . Class I and class II water samples are categorised as good. In the study area 59 samples are in class I and II. Class III waters are not benefitting for agriculture with $25 \%$ of maximum permeability.

Piper's Trilinear diagram: Piper Trilinear Diagram is utilized for depicting hydro substance attributes of groundwater. It is a standard strategy of anticipating hydro concoction facies, which is appropriate for arranging the water quality. Piper Trilinear Diagram created for the water quality is appeared as Fig. 3 delineates likenesses and dissimilarities among the groundwater tests. Piper Trilinear Diagram outline comprises of 2 triangles, left triangle demonstrates cation and right triangle demonstrates anion, all the samples depicted in the triangle are in meq/l and jewel shape in the Piper Trilinear graph connects the both anion and cation field. All the 60 sampling stations were represented in the diagram. Rockworks 16 software is used to create piper trilinear diagram which is shown in Fig. 3. The input for constructing this diagram is $\mathrm{Ca}^{2+}, \mathrm{Mg}^{2+}, \mathrm{Na}^{+}, \mathrm{K}^{+}$, cations and anions are $\mathrm{HCO}_{3}{ }^{-}, \mathrm{CO}_{3}{ }^{-}, \mathrm{Cl}^{-}$and $\mathrm{SO}_{4}{ }^{2-}$. The cation triangle reveals that dominating ion is Magnesium as $92 \%$ of samples are in the $\mathrm{Mg}^{2+}$ portion, very few samples are under in the no dominant nature and sodium nature. In the anionic regime $\mathrm{Cl}$ dominates $\mathrm{HCO}_{3}{ }^{-}, \mathrm{CO}_{3}{ }^{-}$and $\mathrm{SO}_{4}{ }^{2-}$, very few samples fall in sulphate type.

Durov diagram: Durov diagram is plotted using rockwork software version 16 as shown in Fig. 4. It has two base triangle and 1 square. All the cation and anion in the samples are projected as points in the triangular portion of the drawing. The plots in the triangular portion are transferred to square grid. The upper part of the triangle represents carbonates, bicarbonates and sulphates.

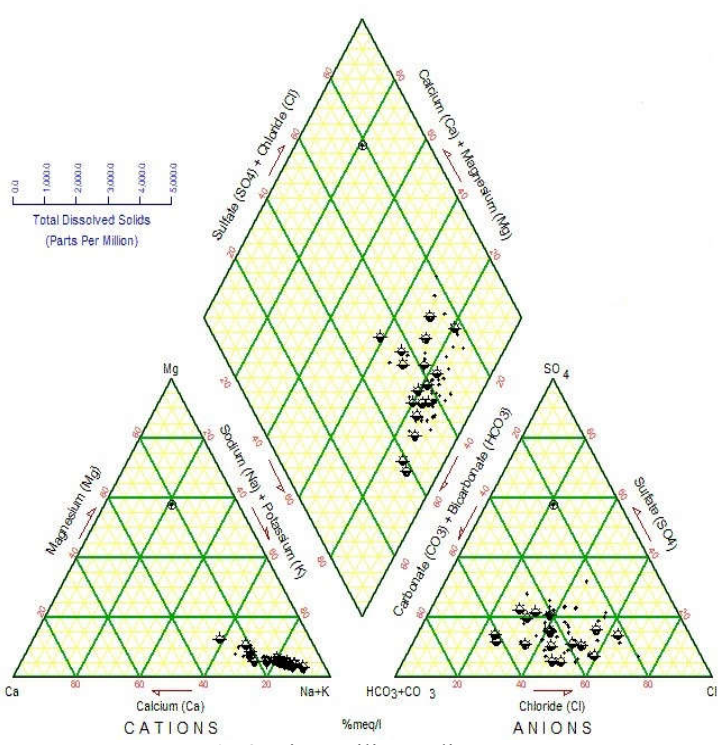

Fig 3. Piper trilinear diagram

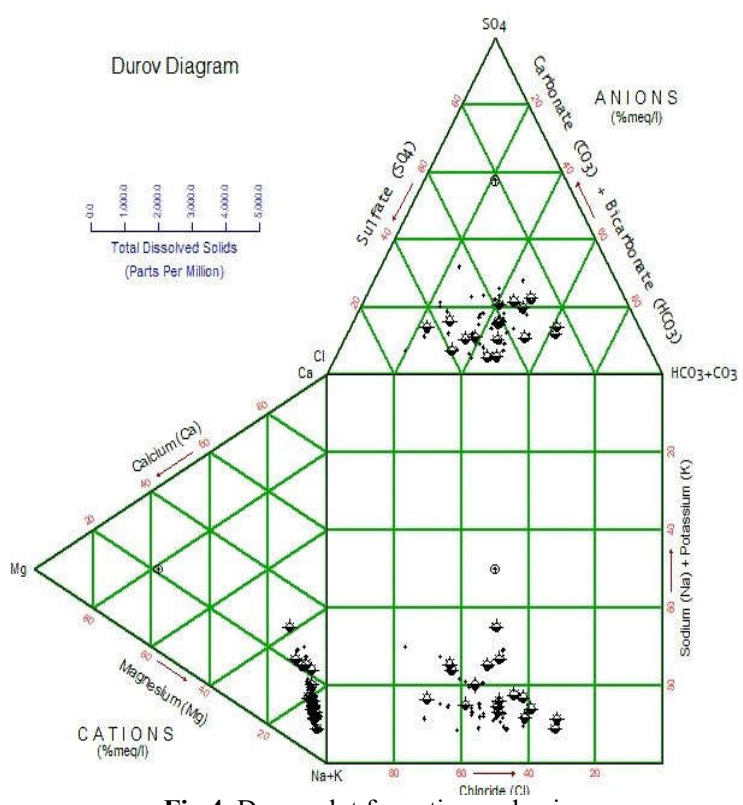

Fig 4. Durov plot for cation and anion

The horizontal part of the triangle represents calcium and magnesium. The samples of similar ionic composition are clustered together. From the figure $\mathrm{Cl}^{-}$dominated the $\mathrm{HCO}_{3}{ }^{-}, \mathrm{CO}_{3}{ }^{-}, \mathrm{SO}_{4}{ }^{2-}$ in the anionic plot. Cationic plot reveals that magnesium ion and calcium ion dominates the other cations. It is revealed from the plot, that the water quality in the study location is dominated with calcium and magnesium .The weathering of metamorphic rock and the hydrogeological framework in the study location 
might be the grounds for calcium magnesium dominance. The dominance of ions in ground water is $\mathrm{Ca}, \mathrm{Mg}$ and $\mathrm{Cl}$ as per piper diagram generated from Rockworks 17.

Conclusion: High level of EC and Total Hardness is noted in few areas. The water category is $\mathrm{Ca}-\mathrm{Mg}-\mathrm{Cl}$ type, as it is analyzed by piper diagram. According to the Wilcox graph the greater part of the example falls in the permissible range. In the total sample of 60 tested, 11 sample location SAR value is below 6 . Magnesium risk is high in the study area. The outcomes depict that water quality falls in the classification of high in saltiness and low in SAR according to USSL outline.

\section{REFERENCE}

Aghazadeh, Nosrat; Asghar Asghari Mogaddam (2010). Assessment of Groundwater Quality and Its Suitability for Drinking and Agricultural Uses in the Oshnavieh Area, Northwest of Iran. $J$. Environ. Prot. 01(01): 30-40.

Ahamed A Jafar; Loganathan, K; Jayakumar,R (2015). Hydrochemical Characteristics and Quality Assessment of Groundwater in Amaravathi River Basin of Karur District, Tamil Nadu , South India. Sustain. Wat. Resources. Manage. 1(3): 273-91.

Arun Kumar,B; Gobinath, R; Shyamala, G;Manvitha,S (2018). Water Quality Prediction Using Statistical Tool and Machine Learning Algorithm. Inter. J. Chemo. informat. Chem. Eng. 7(2): $2-5$.

Jay Krishna Thakur; Sudhir Kumar Singh; Vicky Shettigondahalli Ekanthalu (2016). Integrating Remote Sensing , Geographic Information Systems and Global Positioning System Techniques with Hydrological Modeling. Appl. Wat. Sci. DOI:10.1007/s13201-016-0384-5.

Krishnasamy,R; Shyamala,G; Christian Johnson,S; Sabarinathan, K; SAkthivel, SM; Rajesh Kumar, K (2020). Performance Management of Transmission Line Tower Foundations against Corrosion by Non Destructive Testing. Inter. J. Eng. Adv. Tech. 9(1): 443-447.

Kshetrimayum, KS; Bajpai,VN (2012). Assessment of Groundwater Quality for Irrigation Use and Evolution of Hydrochemical Facies in the Markanda River Basin, Northwestern India. $J$. Geol. Soc. India 79(2): 189-98.
Magesh, NS; Chandrasekar,N (2013). Evaluation of Spatial Variations in Groundwater Quality by WQI and GIS Technique: A Case Study of Virudunagar District, Tamil Nadu, India. Arab. J. Geosci. 6(6): 1883-98.

Mohamed Yousif ; El Sayed El Abd; Ahmed Baraka(2013). Assessment of Water Resources in Some Drainage Basins, Northwestern Coast, Egypt. Appl. Wat. Sci. 3: 439-52.

Omonona, OV; Onwuka,OS; Okogbue,CO (2014). Characterization of Groundwater Quality in Three Settlement Areas of Enugu Metropolis, Southeastern Nigeria, Using Multivariate Analysis. Environ. Monitor.d Assess. 186(2): 651-64.

Hector, HO; Ifeanyi, MO; Amii, IU (2015). Iron , Manganese, Cadmium, Chromium , Zinc and Arsenic Groundwater Contents of Agbor and Owa Communities of Nigeria." Springer Plus 4(104):1-11.

Prasanna, MV; Chidambaram, S; Senthil Kumar, G; Ramanathan, AL; Nainwal, HC (2011). Hydrogeochemical Assessment of Groundwater in Neyveli Basin, Cuddalore District, South India. Arab. J. Geosci. 4(1-2): 319-30.

Ramesh, K; Soorya Vennila (2012). Hydrochemical Analysis and Evaluation of Groundwater Quality in and around Hosur, Krishnagiri District, Tamil Nadu , India. Inter. J. Res. Chem.Enviro. 2(3): $113-22$.

Ramesh, S; Shyamala, G; Ramesh, N; Kalaivani, M ; Mageshkumar, P; Rajesh Kumar, K (2020). Assessment Of Irrigation Water Quality In Orathupalayam Dam, Tamil Nadu, India. International Journal of Scientific and Technolgical Research 9(02): 5399-5403.

Ramkumar Thirunavukkarasu; Senapathi Venkatramanan; Irudhayanathan Anithamary; Sheik Mohamed Syed Ibrahim (2013). Evaluation of Hydrogeochemical Parameters and Quality Assessment of the Groundwater in Kottur Blocks, Tiruvarur District, Tamilnadu, India. Arab. J. Geosci. 6(1): 101-8.

Selvakumar, S; Ramkumar, K; Chandrasekar, N; Magesh, N S; Kaliraj, S (2014). Groundwater Quality and Its Suitability for Drinking and Irrigational Use in the Southern Tiruchirappalli District, Tamil Nadu, India. Appl. Wat. Sci.. DOI 
10.1007/s13201-014-0256-9

Shanmugasundharam, A; Kalpana, G; Mahapatra, SR; Sudharson, ER; Jayaprakash, M (2015). Assessment of Groundwater Quality in Krishnagiri and Vellore Districts in Tamil Nadu, India. Appl. Wat. Sci.. DOI 10.1007/s13201-0150361-4.

Shyamala, G; Jeyanthi, J (2017). Integrated Weighted Overlay Model Using Inverse Distance Weightage for Assessing Groundwater Quality. $J$. Environ. Sci. Manage. 20(1).1-12.

Shyamala, G; Jeyanthi, J; Gobinath, R; Akinwumi, I I; Maheswari, M (2017). Assessment of Groundwater Quality Using Spatial Variation Technique. J. Chem. Pharm. Sci. 10(4): 9-15.

Shyamala, G; Arun Kumar,B; Manvitha, S; Vinay Raj,T (2020). Assessment of Spatial Interpolation Techniques on Groundwater Contamination. Springer International Publishing. http://dx.doi.org/10.1007/978-3-030-243142_33.

Singh Elangbam; Abhik Gupta,JK; Singh,NR (2013).
Groundwater Quality in Imphal West District, Manipur, India, with Multivariate Statistical Analysis of Data. Environ. Sci. Pollut. Res. 20(4): 2421-34.

Srinivas, Y; Aghil, TB ; Hudson Oliver, D; Nithya Nair, C; Chandrasekar, N (2015). Hydrochemical Characteristics and Quality Assessment of Groundwater along the Manavalakurichi Coast, Tamil Nadu, India. Appl. Wat. Sci. http://link.springer.com/10.1007/s13201-0150325-8.

Srinivas, Y; Hudson oliver,D; Stanley Raj,A; Chandrasekar,N (2013). Evaluation of Groundwater Quality in and around Nagercoil Town, Tamilnadu, India: An Integrated Geochemical and GIS Approach. Appl. Wat. Sci. 3(1): 631-51.

Venkateswaran, S; Vediappan, S (2013). Assessment of Groundwater Quality for Irrigation Use and Evaluate the Feasibility Zones through Geospatial Technology in Lower Bhavani Sub Basin, Cauvery River, Tamil Nadu, India. International J. Emerg. Eng. Res. 3 (2): 180-87. 